\title{
Implementasi VPN Berbasis Point To Point Tunneling Protocol (PPTP) Menggunakan Mikrotik Router Board
}

\author{
Riana Febrianti ${ }^{1}$, Sidik ${ }^{2}$, Susafa'ati ${ }^{3}$, Esron Rikardo Nainggolan ${ }^{4}$, Ummu Radiyah $^{5}$ \\ 1,2,3,4,5 Teknik Informatika, Sekolah Tinggi Manajemen Informatika dan Komputer Nusa Mandiri \\ e-mail: ${ }^{1}$ rianna.or@gmail.com, ${ }^{2}$ sidik.sdk@nusamandiri.ac.id, ${ }^{3}$ susafa'ati.suf@nusamandiri.ac.id, \\ ${ }^{4}$ esron.ekg@nusamandiri.ac.id, ${ }^{5}$ ummu.urd@nusamandiri.ac.id
}

\begin{tabular}{ccc}
\hline Diterima & Direvisi & Disetujui \\
$21-03-2021$ & $28-03-2021$ & $31-03-2021$ \\
\hline
\end{tabular}

\begin{abstract}
Abstrak - Kebutuhan interkoneksi antar jaringan akan sangat dibutuhkan terutama pada sebuah instansi yang memiliki banyak kantor cabang. Untuk mempermudah akses komunikasi dan pengambilan data antar kantor maka dibutuhkan sebuah jaringan Virtual Private Network (VPN). Memiliki dua gedung yang jaraknya berjauhan sering terjadi kendala dalam pertukaran data antara gedung A dan gedung B karena selama ini SMK Pejuang Negeri Haurgeulis Indramayu masih manual dalam pertukaran datanya dengan menggunakan flashdisk dalam proses sharing file-nya. Proses pengiriman data menggunakan metode manual tersebut ternyata tidak semua guru dan karyawan di sekolah tersebut memahaminya, selain itu penggunaan media flashdisk tidak bisa digunakan jika data yang dikirimkan melebihi kapasitas dari flashdisk. Dalam menangani masalah keterbatasan kecepatan akses dan keamanan data antara internal instansi, maka pemecahan masalah dapat dilakukan dengan metode PPTP (Point to Point Tunneling Protocol) pada mikrotik yang sudah tersedia di masing-masing gedung. Hasil penelitian menyebutkan bahwa pengujian jaringan dilakukan dengan cara menghubungkan gedung A dan gedung B menggunakan VPN dengan protokol PPTP maka kedua gedung tersebut dapat terhubung dengan baik dan proses pengiriman data dapat dilakukan dengan sukses dan lancar.
\end{abstract}

Kata Kunci: Jaringan Komputer, VPN, PPTP, Mikrotik Router

\section{PENDAHULUAN}

Jaringan komunikasi data yang terintegrasi saat ini sudah menjadi kebutuhan utama bagi sebuah institusi atau perusahaan bisnis, terutama perusahaan yang mempunyai banyak kantor cabang di lokasi geografis yang berbeda dan juga untuk perusahaan yang kegiatan perkantorannya menurut seorang karyawan tidak hanya behind the desk saja namun juga harus mobile (Cahyadi, 2013) . Oleh karena itu kebutuhan untuk akses data antar kantor sangat diperlukan dimanapun dan kapanpun karyawan tersebut berada, kegiatan untuk komunikasi data langsung ke server suatu kantor memerlukan suatu teknologi hardware dan dukungan teknis yang rumit sehingga hal ini akan menyebabkan pembiayaan menjadi mahal (Sutiono, 2015b). Jaringan komunikasi pengiriman data juga diperlukan didalam dunia pendidikan dalam hal ini adalah sekolah-sekolah yang mempunyai beberapa gedung yang berbeda lokasinya.

SMK Pejuang Negeri Haurgeulis adalah sekolah yang di bangun pada tahun 2012 terletak di Indramayu Barat yang memiliki 2 jurusan yaitu jurusan Multimedia dan jurusan TBSM (Teknik Bisnis Sepeda Motor). Sekolah ini juga memiliki 2 gedung yang jaraknya berjauhan, antara gedung A yang terdapat ruang guru, ruang tata usaha, laboratorium komputer, koperasi, dan ruang kelas X, sedangkan di gedung B terdapat ruang laboratorium komputer, ruang guru, perpustakaan, ruang tata usaha. ruang kepala sekolah, ruang kelas XI dan kelas XII. Memiliki dua gedung yang jaraknya berjauhan sering terjadi kendala dalam pertukaran data antara gedung A dan gedung B karena selama ini SMK Pejuang Negeri Haurgeulis Indramayu masih manual dalam pertukaran datanya dengan menggunakan flashdisk dalam proses sharing filenya. Proses pengiriman data menggunakan metode manual tersebut ternyata tidak semua guru dan karyawan di sekolah tersebut memahaminya, selain itu penggunaan media flashdisk tidak bisa digunakan jika data yang dikirimkan melebihi kapasitas dari flashdisk. Hal ini mengakibatkan terganggunya proses pengiriman dan sharing file-nya (Wahyudi \& Hanggara, 2013). Berdasarkan permasalahan ini penulis melakukan analisa dan perancangan Virtual Private Network (VPN) berbasis Point to Point Tunneling Protocol (PPTP) dengan Mikrotik Router Board.

\section{Konsep Dasar Jaringan}

Dibawah ini adalah konsep dasar jaringan:

a. LAN (Local Area Network)

Local Area Network adalah jaringan lokal yang dibuat pada area terbatas (Sofana, 2013). LAN biasa digunakan pada sebuah jaringan kecil yang menggunakan resource 
secara bersama, seperti penggunaan printer media penyimpanan dan sebagainya.

b. MAN (Metropolitan Area Network)

Merupakan jaringan komputer yang memiliki area lebih besar dari LAN, biasanya antar wilayah dalam satu propinsi (Madcoms, 2010). Jaringan MAN menghubungkan beberapa buah jaringan kecil kedalam lingkungan area yang lebih besar (Madcoms, 2016).

c. WAN (Wide Area Network)

Merupakan jaringan yang ruang lingkupnya telah menggunakan sarana satelit, wireless ataupun kabel fiber optik karena jangkauannya lebih luas, bahkan hingga wilayah dan negara lain (Ginta et al., 2013).

d. Internet

Merupakan interkoneksi antar jaringan komputer namun secara umum internet harus dipandang sebagai sumber daya informasi (Hendrianto, 2013).

e. Topologi

Suatu aturan atau rules bagaimana menghubungkan komputer (node) satu sama lain secara fisik dan pola hubungan antara komponen-komponen yang berkomunikasi melalui media atau peralatan jaringan, seperti server, workstation, hub (switch), dan pengkabelannya (media transmisi data) biasa disebut dengan topologi (Tampi et al., 2013).

f. IP Address

IP address merupakan 32 bit bilangan biner dimana bisa dituliskan dengan bilangan desimal dengan dibagi menjadi 4 kolom dan dipisahkan dengan titik. Penggunaan IP address adalah unik, artinya tidak diperbolehkan menggunakan IP address yang sama dalam satu jaringan (Tampi et al., 2013).

g. Perangkat Keras Jaringan

Jaringan komputer merupakan kumpulan dua atau lebih komputer yang saling terhubung satu sama lain (Sutiono, 2015a). Dengan adanya jaringan komputer ini, maka setiap komputer bisa saling bertukar informasi, baik dari server, maupun antar client.

\section{Virtual Private Network (WPN)}

Merupakan sebuah metode atau cara aman untuk mengakses local area network yang berada pada jangkauan, dengan menggunakan internet atau jaringan umum lainnya untuk melakukan transmisi data paket secara pribadi, dengan enkripsi perlu penerapan teknologi tertentu agar walaupun menggunakan medium yang umum, tetapi traffic (lalu lintas) antar remote-site tidak dapat disadap dengan mudah, juga tidak memungkinkan pihak lain untuk menyusupkan traffic yang tidak semestinya ke dalam remote-site (Putra et al., 2018). Sebuah jaringan pribadi (private) yang dapat berjalan dan digunakan pada jaringan yang bersifat umum atau publik (Kuswanto, 2017).

VPN biasanya digunakan pada perusahaan yang memiliki beberapa kantor cabang agar dapat saling mengakses jaringan lokal masing-masing kantor cabang, seperti masih dalam satu jaringan Local Area Network (LAN) (Rosmana \& Latifah, 2015). VPN merupakan jaringan private yang menggunakan jaringan publik seperti internet yang menghubungkan remote access dan user secara bersama-sama dengan memberikan tingkat level privasi (Watrianthos \& Nasution, 2019).

\section{Point to Point Tunneling Protocol (PPTP)}

Sebuah metode komunikasi data atau protokol yang memungkinkan terjadinya komunikasi antara titik pada jaringan internet dengan membuat VPN (Supriyono et al., 2013). Pada metode PPTP, VPN membutuhkan sebuah server yang berfungsi sebagai penghubung antar komputer yang biasa disebut dengan client, baik komputer yang berada di kantor pusat maupun komputer yang berada di kantor cabang. Tunnel adalah mekanisme yang digunakan untuk mengirimkan protokol asing ke jaringan yang biasanya tidak mendukungnya (Handono et al., 2017).

\section{METODE PENELITIAN}

Dalam penelitian ini, penulis menggunakan metode penelitian eksperimen. Metode eksperimen termasuk dalam metode kuantitatif yang dilakukan dengan adanya perlakuan (treatment) (Sugiyono, 2013). Metode eksperimen dapat diartikan sebagai metode penelitian yang digunakan untuk mencari pengaruh perlakuan tertentu terhadap yang laindalam kondisi yang terkendalikan.

\section{Analisa Penelitian}

Dalam melakukan analisa penelitian, penulis membuat dalam tahapan-tahapan berikut:

a. Analisa Kebutuhan

Rancangan jaringan menggunakan PPTP (Point to Point Tunneling Protocol) sangat memungkinkan instansi dapat mendirikan cabang dimana saja tanpa harus membangun infrastruktur pribadi milik perusahaan.

b. Desain

Desain dari perancangan jaringan komputer yang akan diusulkan pada SMK Pejuang Negeri Haurgeulis Indramayu dengan tunneling yang di konfigurasi menggunakan Cisco Packet Tracer.

c. Testing

Rancangan yang diajukan penulis disimulasikan menggunakan Cisco Packet Tracer.

d. Implementasi

Penulis membuat dan mengajukan proposal pembangunan jaringan VPN PPTP tersebut 
kepada SMK Pejuang Negeri Haurgeulis Indramayu yang sebelumnya telah dilakukan penelitian untuk menginformasikan hal-hal penting yang berguna untuk kemajuan sekolah.

\section{Metode Pengumpulan Data}

a. Observasi

Penulis melakukan riset langsung pada SMK Pejuang Negeri Haurgeulis Indramayu mencatat design berjalan jaringan komputer di SMK Pejuang Negeri Haurgeulis Indramayu dan melakukan pengamatan terhadap penyimpanan data-data sekolah dan mencatat fakta-fakta yang ada meneliti kekurangan yang ada pada perancangan design berjalan baik secara langsung maupun tidak langsung agar dapat mengetahui hal yang dianggap penting untuk penulisan penelitian ini.

b. Wawancara

Penulis melakukan wawancara pada bapak Sadim Mulyana dari SMK Pejuang Negeri Haurgeulis terkait jaringan komputer yang sudah berjalan.

c. Studi Pustaka

Studi kepustakan dilakukan berdasarkan pengetahuan teoritas yang telah diterima penulis selama masa perkuliahan, penulis juga mengumpulkan data-data pendukung penelitian dari buku, karya tulis, jurnal dan artikel-artikel internet yang sesuai dengan tema penelitian.

\section{HASIL DAN PEMBAHASAN}

Hasil wawancara dari Bapak Sadim selama penulis riset maka permasalahan yang ada pada SMK Pejuang Negeri Haurgeulis Indramayu yaitu belum terhubungnya gedung A dengan gedung B dan belum digunakannya server data center secara maksimal sehingga data-data yang berada pada SMK Pejuang Negeri Haurgeulis Indramayu masih tersimpan pada email, google drive dan komputer masing-masing yang belum terjamin keamanannya sehingga dalam hal pertukaran data via email untuk jarak yang jauh, sedangkan dalam satu jaringan masih menggunakan flashdisk untuk bertukar datanya.

Dalam upaya mencari pemecahan masalah, penulis menyarankan alternatif yang bisa diterapkan kedepannya terkait mekanisme pengiriman data, yaitu menghubungkan gedung A dan gedung B secara langsung juga memaksimalkan penggunaan dari server data center, yang nantinya akan dihubungkan dengan VPN PPTP. Data instansi yang bersifat sensitif dan rahasia sangat riskan jika selalu mengandalkan google drive yang tidak terlihat fisiknya dan dengan menggunakan VPN dalam penyusunan data lebih tersusun dengan rapih dan baik.

\section{Jaringan Usulan}

Dalam menangani masalah keterbatasan kecepatan akses dan keamanan data antara internal instansi, maka pemecahan masalah dapat dilakukan dengan metode PPTP (Point to Point Tunneling Protocol) pada mikrotik yang sudah tersedia di masing-masing gedung. PPTP merupakan sebuah metode untuk membuat sebuah jalur private diatas jalur publik.

\section{a. Topologi Jaringan}

Topologi jaringan yang diusulkan merupakan pengembangan dari topologi yang ada sebelumnya, dalam hal ini topologi yang awalnya tree setelah di konfigurasi menjadi topologi bus.

b. Skema Jaringan

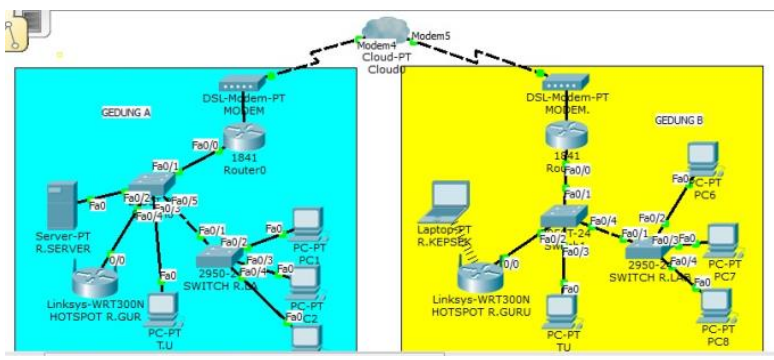

Sumber: dokumen penelitian (2019)

Gambar 1. Skema jaringan usulan

\section{c. Keamanan Jaringan}

1. Pada jaringan publik menggunakan Point to Point Tunneling Protocol (PPTP) yang terdapat pada perangkat mikrotik, sehingga terbentuk sebuah jaringan private yang menghubungkan beberapa jaringan menggunakan jaringan publik secara aman.

2. Pengguna yang ada pada jaringan local masih harus verifikasi user dan password yang diminta oleh komputer server.

\section{Rancangan Aplikasi}

Berikut adalah konfigurasi PPTP pada router mikrotik pusat dimana router mikrotik ini berfungsi sebagai server VPN.

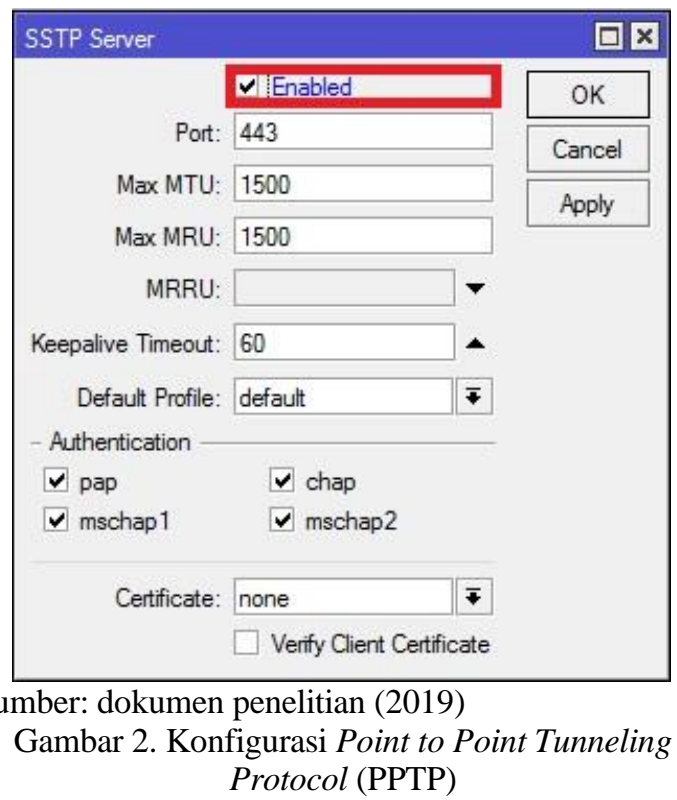


Untuk menggunakan fitur PPTP pada router mikrotik, harus di enable terlebih dahulu konfigurasi PPTP server pada mikrotik yang akan mejadi server PPTP. Pada gambar diatas adalah mikrotik di gedung A yang dipilih untuk menjadi server, masuk ke menu PPP pada menu bar mikrotik di sebelah kiri lalu pilih PPTP server pada menu bar lalu checklist pada bagian enable. Pada tahap ini PPTP server pada router mikrotik gedung A sudah terbentuk, tetapi untuk mengakses PPTP melalui dial-up di mikrotik yang dibuat username dan password, nantinya akan dimasukan pada saat membuat konfigurasi VPN di mikrotik gedung B dengan memasukan IP Address dan username password yang sudah dibuat di mikrotik.

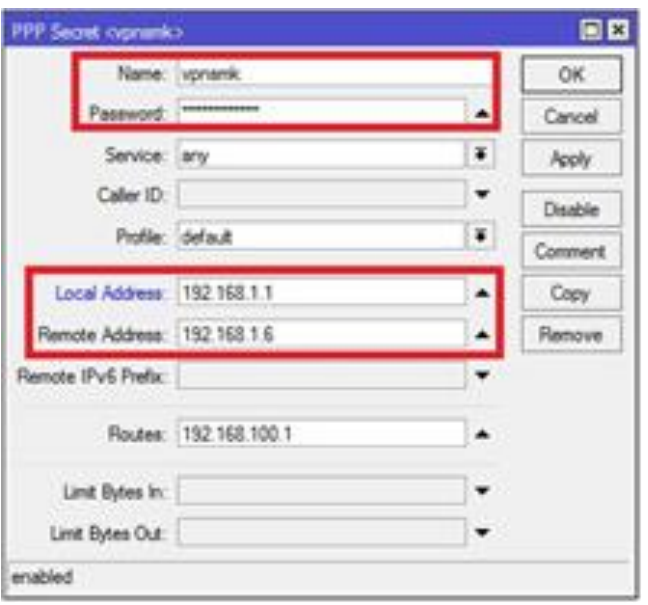

Sumber: dokumen penelitian (2019)

Gambar 3. Konfigurasi User PPTP

Pilih Tab Secret dimana $t a b$ ini berisi konfigurasi pembuatan username dan password yang dapat mengakses jaringan lokal melalui internet. Pada kolom name isikan nama sesuai keinginan, pada gambar diatas diisi dengan nama "vpnsmk" dan pada password diisi "smkpenha2012". Berikut adalah konfigurasi VPN pada mikrotik gedung B untuk mengakses jaringan lokal melalui internet.

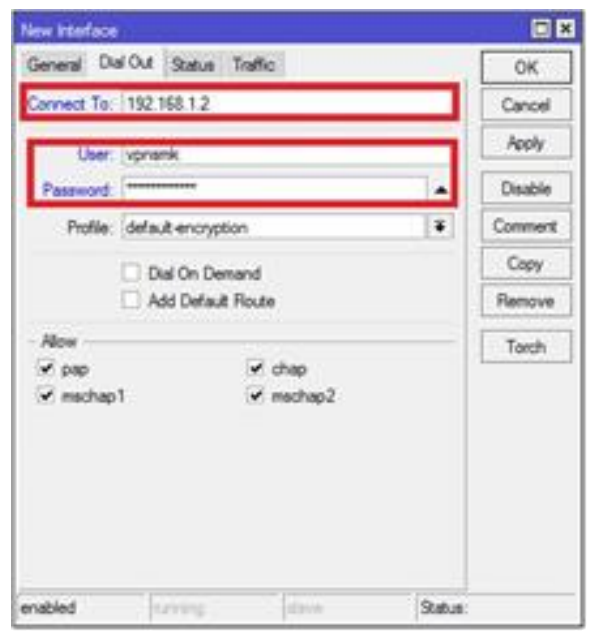

Sumber: dokumen penelitian (2019)

Gambar 4. Konfigurasi VPN Client
Pada bagian connect to diisi IP address gedung A sedangkan untuk kolom username dan password isikan sesuai dengan username dan password yang sebelumnya sudah dibuat.

\section{Manajemen Jaringan}

Pada penerapan metode Tunneling Protocol ini sangat membantu administrator jaringan untuk lebih mudah mengawasi, memonitoring, jaringan komputer yang sedang berjalan.

\section{Pengujian Jaringan}

a. Pengujian Jaringan Awal

Pada pengujian jaringan awal penulis menggunakan simulasi software Cisco Packet Tracer. Berikut ini adalah gambaran simulasi jaringan awal:

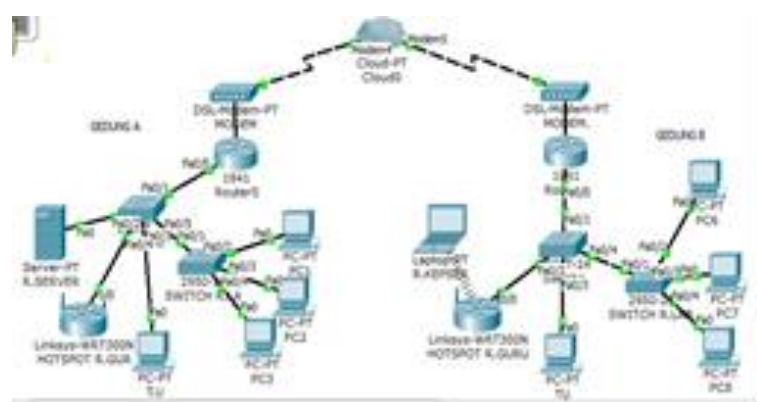

Sumber: dokumen penelitian (2019)

Gambar 5. Simulasi Jaringan Awal

b. Pengujian Jaringan Akhir

Pengujian simulasi menggunakan software Cisco Packet Tracer.

1. PC Tata Usaha dari gedung B terhubung ke Server yang berada di gedung A.

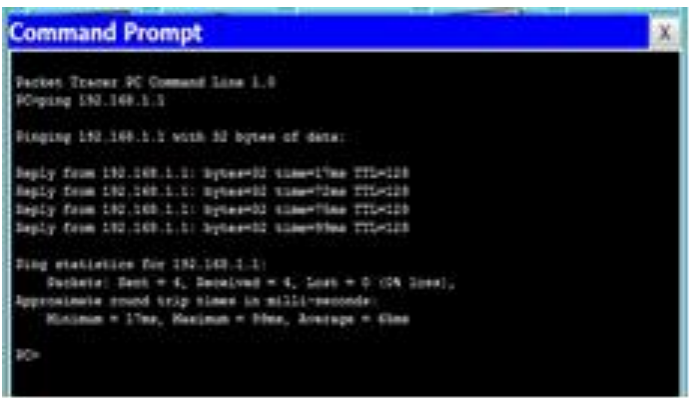

Sumber: dokumen penelitian (2019)

Gambar 6. Hasil ping dari PC TU gedung B ke Server Penulisan : cetak miring/italic

2. Komputer SMK Pejuang Negeri Haurgeulis Indramayu terhubung pada router mikrotik.

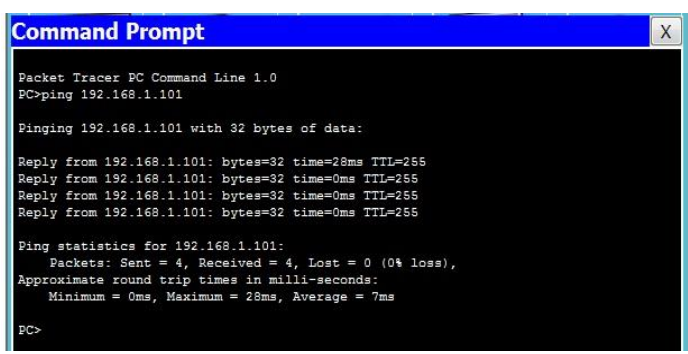

Sumber: dokumen penelitian (2019)

Gambar 7. Hasil ping komputer ke router 
3. PC gedung A dan gedung B pada SMK Pejuang Negeri Haurgeulis Indramayu saling terhubung.

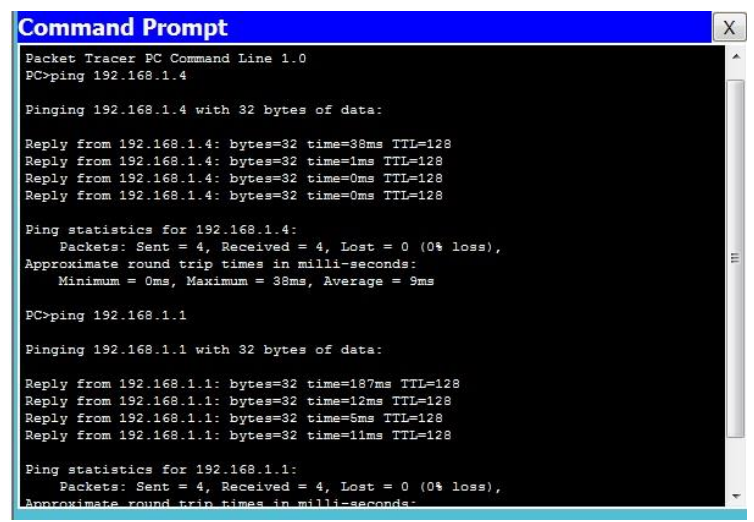

Sumber: dokumen penelitian (2019)

Gambar 8. Hasil ping antar PC pada setiap gedung

\section{KESIMPULAN}

Setelah mempelajari dan menganalisa jaringan menggunakan VPN maka penulis memberikan beberapa kesimpulan jaringan Virtual Private Network (VPN) sebagai berikut:

1. SMK Pejuang Negeri Haurgeulis Indramayu terdiri dari gedung A dengan gedung B yang keduanya belum terhubung dan belum digunakannya server data center secara maksimal sehingga data-data yang berada pada SMK Pejuang Negeri Haurgeulis Indramayu masih tersimpan pada email, google drive dan komputer masing-masing yang belum terjamin keamanannya sehingga dalam hal pertukaran data via email untuk jarak yang jauh, sedangkan dalam satu jaringan masih menggunakan flashdisk untuk bertukar datanya.

2. Pengujian jaringan dilakukan dengan cara menghubungkan gedung $\mathrm{A}$ dan gedung $\mathrm{B}$ menggunakan VPN dengan protokol PPTP maka kedua gedung tersebut dapat terhubung dengan baik dan proses pengiriman data dapat dilakukan dengan sukses dan lancar.

3. Virtual private network (VPN) menggunakan point to point tunneling protocol (PPTP) sebagai protokol yang digunakan untuk menghubungkan jaringan dengan aman walaupun menggunakan jaringan publik.

\section{REFERENSI}

Cahyadi. (2013). Analisis Quality Of Service (QoS) Pada Jaringan Lokal Session Initiation Protocol (SIP) Menggunakan GNS3. Transient: Jurnal Ilmiah Teknik Elektro. https://ejournal3.undip.ac.id/index.php/transie nt/article/view/3571

Ginta, P. W., Kusuma, G. P., \& Negara, E. K. (2013). IMPLEMENTASI TOOLS NETWORK MAPPER PADA LOKAL AREA NETWORK (LAN). Jurnal Media Infotama, 9(2). http://www.ilmukomputer.com/security

Handono, F. W., Sumarna, S., \& Nurdin, H. (2017). Virtual Private Network Tunneling Dengan Protokol IP in IP Melalui Jaringan Internet INFORMATICS FOR EDUCATORS AND PROFESSIONAL: Journal of Informatics. Informatics For Educators and Profesionals, 2(1), 61-67. http://ejournalbinainsani.ac.id/index.php/ITBI/article/view/6 57

Hendrianto, E. (2013). Pembuatan Sistem Informasi Perpustakaan Berbasis Website Pada Sekolah Menegah Pertama Negeri 1 Donorojo Kabupaten Pacitan. IJNS - Indonesian Journal on Networking and Security. http://ijns.org/journal/index.php/ijns/article/vie w/288/282

Kuswanto, H. (2017). Implementasi Jaringan Virtual Private Network (VPN) Menggunakan Protokol EoIP. Paradigma - Jurnal Komputer Dan Informatika, 19(1), 46. https://ejournal.bsi.ac.id/ejurnal/index.php/par adigma/article/view/1491

Madcoms. (2010). Sistem Jaringan Komputer untuk Pemula - Google Books. Google Book. https://www.google.co.id/books/edition/Siste m_Jaringan_Komputer_untuk_Pemula/Q6wby V05S3cC?hl=id\&gbpv=1\&dq=Cepat $+\% 26+\mathrm{M}$ udah+Membangun+Sistem+Jaringan+Komput er\&printsec $=$ frontcover

Madcoms. (2016). Manajemen Sistem Jaringan Komputer dengan Mikrotik RouterOS. Andi Offset.

Putra, J. L., Indriyani, L., \& Angraini, Y. (2018). Penerapan Sistem Keamanan Jaringan Menggunakan VPN Dengan Metode PPTP Pada PT. Asri Pancawarna. IJCIT (Indonesian Journal on Computer and Information Technology), $3(2)$. https://doi.org/10.31294/IJCIT.V3I2.4677

Rosmana, \& Latifah, F. (2015). Implementasi Virtual Private Network (VPN) Dengan Otentikasi Radius Server Pada Pt. Anugerah Tunggal Mandiri Jakarta. Jurnal Techno Nusa Mandiri, 12(1), 23-34.

Sofana. (2013). Jaringan Komputer. Informatika.

Sugiyono. (2013). Metodologi Penelitian Kuantitatif,kualitatif dan $R \& D$. Alfabeta.

Supriyono, H., Widhaya, J. A., \& Supardi, A. (2013). Penerapan Jaringan VPN Untuk Keamanan Komunikasi Data Bagi PT. Mega Tirta Alami. Jarkom, 16(2), 88-101.

Sutiono. (2015a). 12 Perangkat Keras Jaringan Komputer: Fungsi Beserta Gambarnya DosenIT.com. Dosen IT. 
https://dosenit.com/jaringan-

komputer/hardware-jaringan/perangkat-kerasjaringan-komputer

Sutiono. (2015b). 9 Kelebihan dan Kekurangan Jaringan Client Server - DosenIT.com. DosenIT. https://dosenit.com/jaringankomputer/konsep-jaringan/kelebihan-dankekurangan-jaringan-client-server

Tampi, B. A. Y., Najoan, M. E. I., Sinsuw, A. A. E., Lumenta, A. S. M., \& Komputer, A. P. J. (2013). Implementasi Routing Pada IP Camera Untuk Monitoring Ruang di Universitas Sam Ratulangi. E-Journal Teknik Elektro Dan Komputer, 2(2), 1-8.

Wahyudi, G., \& Hanggara, T. (2013). Analisis Perbandingan Kinerja Antara Network File System (NFS) Dan Primary Domain Controller (PDC) Samba. Program Studi Teknik Informatika, Jurusan Ilmu Komputer, 6(1), 25-34.

Watrianthos, R., \& Nasution, M. (2019). ANALISA KEMAMPUAN TRANSVER DATA VPN BERBASIS OPEN SOURCE PADA KONDISI ENCRIPSI-DEKSCRIPSI DAN KOMPRENSI-DEKOMPRENSI. JURNAL INFORMATIKA, 6(1), 23-51. https://doi.org/10.36987/informatika.v6i1.740 